\title{
CONSOLIDAÇÃO DE VALORES ÉTICOS NAS EMPRESAS ESTATAIS E O COMBATE À CORRUPÇÃO: PRÁTICAS PARA EFETIVAÇÃO DE POLÍTICAS SOCIALMENTE RESPONSÁVEIS
}

\author{
Ísis Carolina Massi Vicente* \\ Clodomiro José Bannwart Júnior**
}

\section{RESUMO}

As empresas estatais da forma como eram geridas, tornaram-se ambientes propícios à corrupção. Denúncias de corrupção levaram a sociedade a clamar por mudanças, que vieram através de leis. As normas remetem à transparência, compliance e à priorização de medidas preventivas, mas também a procedimentos de investigação e aplicação de penalidades. A prática de responsabilidade social inserida no Estatuto das Estatais impõe a observância de valores éticos como condição indispensável ao combate da corrupção. Decorre, investigar se as Estatais, quando vítimas de corrupção, dispõem de autorização constitucional para conduzirem o Processo Administrativo de Responsabilização - PAR e, aplicarem sanções punitivas.

Palavras-chave: Estatais - corrupção - lei - ética - sanção.

\section{CONSOLIDATION OF VALUES IN STATE COMPANIES AND THE COMBATING CORRUPTION: PRACTICES FOR IMPLEMENTING SOCIALLY RESPONSIBLE POLICIES}

\begin{abstract}
State-owned enterprises, in the way they were managed, became environments conducive to corruption. Accusations of corruption led society to call for changes, which came through laws. The standards refer to transparency, compliance and prioritization of preventive measures, but also procedures for investigation and application of penalties. The practice of social responsibility inserted in the State Statute imposes the observance of ethical values as an indispensable condition for the fight against corruption. It is necessary to investigate whether the State companies, when victims of corruption, have constitutional authorization to conduct the Administrative Process of Accountability - PAR and apply punitive sanctions.
\end{abstract}

Keywords: State - corruption - law - ethics - sanction

\section{INTRODUÇÃO}

\footnotetext{
* Mestranda do Programa de Mestrado em Direito Negocial da Universidade Estadual de Londrina- UEL, (Brasil). E-mail: isiscmvicente@ gmail.com

** Pós-Doutor em Filosofia pela Universidade Estadual de Campinas- UNICAMP, (Brasil). Professor do Programa de Mestrado em Direito Negocial da Universidade Estadual de Londrina. E-mail: cbannwart@hotmail.com
} 
As empresas estatais compostas por empresas públicas, sociedades de economia mista e suas subsidiárias foram e ainda tem sido alvo de diversas denúncias de corrupção, o que está motivando a sociedade e setores do mercado a clamar por mais transparência e controle na forma de geri-las.

Não apenas as empresas estatais, mas a Administração Pública como um todo tem passado por reestruturações normativas, fruto do clamor social que pugna por mudanças e pela efetivação a princípios administrativos como a moralidade e a publicidade, os quais são notados em legislações recentes, como a Lei de Acesso à Informação, Lei n ${ }^{\circ}$ 12.527/2011, a Lei Anticorrupção, Lei no 12.846/2013 e o Estatuto Jurídico das Empresas Estatais, Lei no 13.303/16.

A Lei de Acesso a Informação trouxe o sigilo como exceção, apenas permitindo-o em situações excepcionais, já que o objetivo é dar conhecimento de todos os atos e gastos provenientes de folhas de pagamento, contratos e aditivos geridos pela Administração Pública.

A publicização possibilita que toda a sociedade possa acompanhar e fiscalizar o que está sendo realizado, objetivando o combate à corrupção, na medida em que casos de desvios ou irregularidades possam ser denunciados.

A Lei Anticorrupção, instituída pela Lei $n^{\circ} 12.846 / 13$, prevê a responsabilização objetiva administrativa e civil das pessoas jurídicas pela prática de atos que atentem contra o patrimônio da Administração Pública, o que inclui as empresas estatais, além de prever a instauração de Processo Administrativo de Responsabilização - PAR e a consequente aplicação de sanções às pessoas jurídicas responsáveis por terem causado o prejuízo.

O intuito de combater a corrupção nas empresas estatais através da adoção de medidas que contemplem a transparência, a eficiência e a moralidade foi reforçado pelo Estatuto Jurídico das Empresas Estatais, instituído pela Lei $\mathrm{n}^{\circ} 13.303 / 16$, que entrou em vigência no dia 30 de junho de 2016, e pretende que a atuação dessas empresas seja dissociada do agir da Administração Direta, razão pela qual reforça a importância da incorporação das práticas de compliance trazidas inicialmente pela Lei Anticorrupção. Com isso passa a ser exigido um novo perfil para ocupar, por exemplo, cargos de Presidente, VicePresidente, Diretores e membros dos Conselhos de Administração, além de ações que prezem pela sustentabilidade ambiental, responsabilidade social, função social e, essencialmente, contemplem o interesse público e os imperativos de segurança nacional. 
Para demonstrar os mecanismos legais instituídos e implicados no combate à corrupção, na transparência e na responsabilidade social das empresas estatais, o presente trabalho irá se ater a análise das normas federais destinadas às empresas públicas, sociedades de economia mista e suas subsidiárias, desde que pertencentes à União. Há como objetivo central demonstrar a preocupação do legislador pátrio em combater a corrupção nas estatais, especialmente com a instituição de programas de prevenção à corrupção e a consolidação de valores éticos e princípios morais que reforcem práticas que atendam à expectativa de comportamento esperada pela sociedade.

Desta forma, será realizada uma explanação sobre a implementação de medidas legais com objetivo de preservar o patrimônio público, impedindo práticas de corrupção através de ações preventivas, investigativas e sancionatórias, com o fito de preservar a credibilidade e contemplar os preceitos vinculados à função social e à execução de atividades socialmente responsáveis.

O trabalho está subdivido em dois momentos. No primeiro, abordar-se-á as inovações legislativas de combate à corrupção na esfera privada e, sobretudo, no âmbito das empresas estatais. No segundo, demonstrar-se-á a importância do compliance que, primeiramente, aparece no contexto da Lei Anticorrupção, para em seguida avaliar a sua inserção e aplicação nas empresas estatais a partir do Estatuto Jurídico das Empresas Estatais e seu decreto regulamentador, Decreto $n^{\circ} 8.945 / 16$.

Em que pese a importância de tais legislações, amplamente favoráveis ao combate à corrupção, far-se-á notar, como hipótese do trabalho, que a extensão do compliance às empresas estatais poderá criar dificuldade quanto à aplicação do Processo Administrativo de Responsabilidade - PAR. Isso porque, as empresas estatais, na medida que detêm natureza jurídica de direito privado, não dispõem de capacidade constitucional para instauração e aplicação de sanções, caso figurem como vítimas de corrupção.

Com o objetivo de apontar o problema, ora em comento, será utilizado como recurso metodológico a análise de textos que intercalam a reflexão em seara jurídica. Do ponto de vista dos objetivos, a pesquisa terá um caráter exploratório contando com recursos de levantamento bibliográfico, tendo como base de dados os periódicos disponíveis na temática, livros de Filosofia e de Direito que circunscrevem o objeto previamente delimitado. Do ponto de vista do procedimento técnico, a pesquisa será bibliográfica (materiais diversos - livros, internet, etc.) e documental, contando com fontes primárias e secundárias. 


\section{INOVAÇÕES LEGISLATIVAS DE COMBATE A CORRUPÇÃO E A RESPONSABILIDADE SOCIAL}

As empresas estatais, compostas por empresas públicas, sociedades de economia mista e suas subsidiárias ${ }^{\dagger}$, exploradoras de atividade econômica de produção ou comercialização de bens ou de prestação de serviços, ainda que a atividade econômica esteja vinculada ao regime de monopólio da União, sujeitam-se ao Estatuto Jurídico das Empresas Estatais, que foi instituído com o fim de contemplar o disposto no $\S 1^{\circ}$ do artigo 173 da Constituição Federal, que preconizava o estabelecimento do referido estatuto por meio de lei.

Importante reforçar que as empresas estatais podem atuar tanto como prestadoras de serviços públicos ou como exploradoras de atividade econômica, sendo que neste último caso as estatais não atuam buscando diretamente o fim público, em razão da atuação dar-se no campo econômico, típico da iniciativa privada.

Assim, caso o Estado pretenda atuar explorando atividade econômica deverá ser em situação excepcional, pois apenas por razões de relevante interesse coletivo e quando for necessário aos imperativos da segurança nacional é que poderá fazê-lo, conforme verifica-se no caput do artigo 173 da Constituição Federal, que giza:

Art. 173. Ressalvados os casos previstos nesta Constituição, a exploração direta de atividade econômica pelo Estado só será permitida quando necessária aos imperativos da segurança nacional ou a relevante interesse coletivo, conforme definidos em lei.

O caráter de excepcionalidade da exploração de atividade econômica pelo Estado é reforçado através do contido no caput e no $\S 1^{\circ}$ do artigo $2^{\circ}$ da Lei $n^{\circ} 13.303 / 16$, que dispõe sobre o Estatuto Jurídico da Empresa Pública e da Sociedade de Economia Mista, nos seguintes termos:

\footnotetext{
${ }^{\dagger}$ De acordo com Lei 13.303/16, empresas públicas e sociedades de economia mista são definidas da seguinte forma: Art. $3^{\circ}$. Empresa pública é a entidade dotada de personalidade jurídica de direito privado, com criação autorizada por lei e com patrimônio próprio, cujo capital social é integralmente detido pela União, pelos Estados, pelo Distrito Federal ou pelos Municípios; Art. $4^{\circ}$. Sociedade de economia mista é a entidade dotada de personalidade jurídica de direito privado, com criação autorizada por lei, sob a forma de sociedade anônima, cujas ações com direito a voto pertençam em sua maioria à União, aos Estados, ao Distrito Federal, aos Municípios ou a entidade da Administração Indireta.
} 
Art. $2^{\text {o. }}$ A exploração de atividade econômica pelo Estado será exercida por meio de empresa pública, de sociedade de economia mista e de suas subsidiárias.

$\S 1^{\text {o. }}$ A constituição de empresa pública ou de sociedade de economia mista dependerá de prévia autorização legal que indique, de forma clara, relevante interesse coletivo ou imperativo de segurança nacional, nos termos do caput do art. 173 da Constituição Federal.

Com fulcro nos dispositivos acima, não é mais possível que o Estado crie empresas estatais voltadas à exploração de atividade econômica sem que haja claramente interesse público ou o necessário imperativo à segurança nacional, e essas premissas destinam-se a fazer com que o Estado direcione suas ações à consecução de atividades de interesse público, que por sua vez revela a função social das empresas estatais, conforme verifica-se através da leitura do caput do artigo 27 da Lei $\mathrm{n}^{\circ}$ 13.303/2016:

Art. 27. A empresa pública e a sociedade de economia mista terão a função social de realização do interesse coletivo ou de atendimento a imperativo da segurança nacional expressa no instrumento de autorização legal para sua criação.

É importante observar que apesar das restrições legais impostas à criação de novas empresas estatais exploradoras de atividade econômica, têm-se ainda hoje uma gama muito grande de estatais neste segmento constituídas em momento anterior à ressalva normativa, e que precisam adequar seu Estatuto e, por conseguinte, suas atividades aos preceitos normativos da Constituição Federal e, ademais à Lei $n^{\circ}$ 13.303/16 e ao Decreto $n^{\circ}$ 8.945/16 que regulamenta a referida lei, não podendo haver divergência entre o Estatuto Social e a lei que regula a criação da estatal.

A função social da empresa estatal consiste no cumprimento de uma norma legal, e com fulcro no presente contexto normativo, o significado do termo refere-se ao fato de que a Empresa Estatal ao ser constituída já deve possuir um fim social que justifique sua existência, razão pela qual ela deve se manter fiel a esse axioma.

Assim, para compreender melhor a ideia de função social descrita no caput do artigo 27 do Estatuto Jurídico das Estatais, é importante analisar o artigo 170 da Constituição Federal ao determinar que a ordem econômica deve se fundar na valorização do trabalho humano, na livre iniciativa, tendo a finalidade de assegurar a todos uma existência digna, observando princípios como a soberania nacional, a livre concorrência, a defesa do 
consumidor e do meio ambiente, o que permite concluir que se estará atendendo a função social quando esses princípios forem contemplados.

Outra preocupação iminente com relação as empresas estatais é o combate a corrupção, devido a quebra da confiança proveniente de escândalos que vieram à público e despertaram grande descontentamento na sociedade brasileira, e passou a pleitear a punição dos envolvidos e uma mudança estrutural de comportamento nas empresas, por meio de ações que estão sendo realizadas através de processo normativo.

O caso mais emblemático de corrupção envolveu a Petrobrás, maior empresa estatal do país, atualmente uma das maiores empresas nacionais de capital aberto, e a maior petrolífera brasileira que, até a edição da Lei $n^{\circ}$ 9.478, de 6 de agosto de 1997, detinha o monopólio do petróleo no Brasil. Em razão das denúncias de corrupção, a empresa acumulou grande prejuízo econômico conforme verifica-se em matérias jornalísticas veiculadas no início da Operação Lava-jato, em 2014:

\begin{abstract}
"Pressionada por uma avalanche de denúncias de corrupção, a Petrobrás vive sua mais grave crise de credibilidade. São pelo menos cinco inquéritos na Polícia Federal (PF), além de investigações no Ministério Público Federal (MPF) e no Tribunal de Contas da União (TCU). A crise também é financeira, com perdas de R\$ 185 bilhões, cerca de 51\% do seu valor de mercado, em três anos" (Gazeta do Povo, 2014, s. p.).
\end{abstract}

“A divulgação do balanço auditado é apontada como tarefa essencial para o resgate da credibilidade da Petrobras e para que a empresa consiga captar recursos e atrair investidores. Caso fosse novamente adiada, parte dos seus credores poderiam pedir o vencimento antecipado de suas dívidas o que, em tese, poderia levar a empresa à insolvência e exigir uma operação de injeção de capital pelo governo" (CAOLI; ALVARENGA; LAPORTA, 2015, s.p.).

Note-se que além de ser alvo de práticas corruptivas, as empresas estatais também foram influenciadas pela ingerência de políticas governamentais em sua gestão, que pode ser visto por meio da política de controle de preços que até pouco tempo atrás era praticado na Petrobras, conforme dados apresentados em 2014.

\footnotetext{
‡O nome "lava jato" na operação realizada pela Polícia Federal decorreu em razão do uso de uma rede de postos de combustíveis e lava jato de automóveis para movimentar recursos ilícitos pertencentes a uma das organizações criminosas inicialmente investigadas. A operação lava jato é a maior investigação de corrupção e lavagem de dinheiro que o Brasil já teve. A investigação teve início em março de 2014, na Justiça Federal em Curitiba. Estima-se que os recursos desviados da Petrobrás, esteja em bilhões. O esquema de corrupção existente há anos, envolveu grandes empreiteiras organizadas em cartel pagando propina para altos executivos da estatal e outros agentes públicos, sendo que o valor da propina variava de $1 \%$ a $5 \%$ do montante total de contratos bilionários superfaturados. Fonte: http://lavajato.mpf.mp.br/entenda-o-caso. Acesso em 20/04/2017.
} 
"A conta da área de abastecimento da Petrobras não fechou novamente e, desta vez o rombo foi $55 \%$ maior que um ano atrás. O motivo: a empresa compra petróleo e derivados do exterior e revende-os no Brasil por um preço mais baixo, controlado pelo governo, sócio majoritário da empresa. O governo faz isso na tentativa de conter a inflação no país, mas essa diferença afeta as contas da estatal" (UOL, 2014, s.p.)

Devido aos prejuízos econômicos acumulados e buscando retomar a credibilidade da sociedade e do mercado - antes mesmo da edição do Estatuto Jurídico das Empresas Estatais, que trouxe diversos mecanismos visando o fortalecimento de valores e a adoção de novas práticas de combate a corrupção - a Petrobras passou a implementar medidas para dissociar sua política de atuação da influência governamental, como ocorreu com a nova política de estabelecimento de preços instituída no segundo semestre de 2016:

"Pelas novas regras, os preços serão equivalentes aos praticados internacionalmente (e nunca poderão ficar abaixo deles). Na conta para formá-los, serão incluídos custos com importação, transporte e tarifas portuárias, além de uma margem para compensar riscos da operação, problemas logísticos e taxas. Os preços ainda serão revisados pelo menos uma vez por mês e poderão ser alterados. A cada bimestre, a estatal vai publicar uma análise dos valores. O mercado reagiu bem ao anúncio. As ações preferenciais da companhia chegaram a valorizar $3,4 \%$ e as ordinárias $2,4 \%$ [...]" (MELO, 2016, s. p.).

O Estatuto Jurídico foi a mais recente mudança legislativa direcionada à atuação das empresas estatais, tendo como um de seus escopos impedir a intervenção governamental nessas empresas para que, de fato, elas configurem em instrumentos destinados à contemplação de interesses públicos, de ordem estatal e não governamental.

\begin{abstract}
"Embora atuando no mercado por meio de estruturas definidas pelo direito privado, as empresas estatais sempre foram sujeitas a ampla ingerência do Estado e dos sucessivos governos. Essa influência se refletia na escolha dos dirigentes e na própria forma de atuação dessas empresas que, muitas vezes, se destinavam ao atendimento de demandas de cunho político por parte do governo de ocasião" (CARDOSO, 2016, p.96).
\end{abstract}

Uma das formas de coibir as influências de cunho político e governamental nas estatais dá-se através de ações mais transparentes. Desde o advento da Constituição Federal, através do contido no inciso XXXIII ${ }^{\S}$ do artigo $5^{\circ}$, se previa o direito de todos receberem dos órgãos públicos informações de seu interesse, particular ou coletivo, entretanto, tal preceito

\footnotetext{
${ }^{\S}$ XXXIII - todos têm direito a receber dos órgãos públicos informações de seu interesse particular, ou de interesse coletivo ou geral, que serão prestadas no prazo da lei, sob pena de responsabilidade, ressalvadas aquelas cujo sigilo seja imprescindível à segurança da sociedade e do Estado
} 
efetivamente só recebeu maior notoriedade e aplicabilidade com a instituição da Lei $\mathrm{n}^{\circ}$ 12.527/11 conhecida como Lei de Acesso a Informação.

A publicação do valor dos altos salários pagos aos executivos das empresas públicas, bem como os valores das contratações realizadas e dos aditivos celebrados chamaram atenção da opinião pública, principalmente pelos maus resultados financeiros apresentados por elas.

A falta de tecnicidade e de comprometimento dos Diretores, Presidentes e membros do Conselho de Administração com o desempenho das atividades das empresas estatais, fruto de indicações políticas de pessoas sem o perfil adequado, não se restringiram a afetar o desempenho da empresa, mas possibilitaram a realização de negociações espúrias com o setor privado, por não estarem moralmente comprometidos com os resultados requeridos pelo setor público (ANTONIK, 2016). E sem mecanismos de prevenção adequados, tal quadro era gerador da sensação de impunidade, favorecendo permanentemente novas ocorrências.

Não há como deixar de considerar que "a nomeação política aniquila a boa gestão, elimina a possibilidade de a entidade desenvolver seu papel social e sua capacidade de alcançar metas” (ANTONIK, 2016, p. 65). É uma situação que leva ao comprometimento da própria função social da empresa quanto ao cumprimento das finalidades para as quais foram instituídas.

Os atos de corrupção realizados nas estatais causaram graves prejuízos de ordem estrutural e principalmente financeira, tendo em vista que ocupantes de cargos de alto escalão recebiam "gratificação" de grandes empresas privadas para favorecer a celebração de contratos entre elas e as estatais.

Diante do grande número de denúncias de corrupção, no ano de 2013 ocorreram diversas manifestações populares espontâneas, que foram às ruas pugnando pelo fim da corrupção (MARINELA, PAIVA e RAMALHO, 2015), o que acabou acelerando a aprovação da Lei ${ }^{\circ} 12.846 / 13$, conhecida como Lei Anticorrupção.

O processo de aprovação da Lei 12.846/13 foi de grande relevância para o combate e punição dos envolvidos em corrupção. Parida às pressas para atender as reinvindicações de combate à corrupção propugnadas pelas ruas, a aprovação célere da Lei fazia parte, além do mais, de uma série de exigências assumidas pelo Brasil em âmbito internacional visando o combate a corrupção. 
A Convenção Interamericana contra a Corrupção, assinado em Caracas em 1996, foi o primeiro a tratar sobre o assunto, tendo sido ratificado pelo Brasil, que o promulgou apenas em 2002, através do Decreto $n^{\circ} 4.410$.

Devido a limitação quanto aos signatários, pleiteou-se um acordo global, que foi aprovado em 2003 pela Assembleia Geral das Nações Unidas, denominado de Convenção das Nações Unidas contra a Corrupção, e apesar de ratificado no mesmo ano, o Congresso Nacional só aprovou o texto através do Decreto Legislativo $n^{\circ} 348 / 2015$, promulgando-o pelo Decreto no 5.687 de 2016 (MARINELA, PAIVA e RAMALHO, 2015).

E em 30 de novembro do ano 2000, o Brasil ratificou e promulgou a Convenção sobre Combate à Corrupção de Funcionários Públicos Estrangeiros em Transações Comerciais Internacionais da Organização de Cooperação e de Desenvolvimento Econômico - OCDE, que é uma organização pública internacional, formada pela associação de países membros, que objetivam a promoção de políticas para melhorar as condições econômicas das nações e das pessoas (MARINELA, PAIVA e RAMALHO, 2015).

A Lei Anticorrupção previu a responsabilização objetiva administrativa e civil da pessoa jurídica privada sem excluir a responsabilização individual de dirigentes, administradores ou qualquer pessoa natural envolvida no cometimento de ato lesivo ao patrimônio da administração pública.

Antes da Lei Anticorrupção, já havia a Lei no 8.429/92, conhecida como Lei de Improbidade Administrativa, que pretendia responsabilizar o agente público, pessoa física, sendo a pessoa jurídica apenas punida se figurasse como terceira beneficiada, mas ainda não era suficiente.

Na ocasião da entrada em vigência da Lei anticorrupção, foi reforçada a importância das empresas privadas nortearem preventivamente suas ações objetivando o combate a corrupção, através das práticas de compliance, termo que advém da expressão em inglês "to comply", que significa "cumprimento ou atendimento às obrigações legais, promessas e expectativas, ou ainda, obediência às normas legais, bem como às políticas, diretrizes e exigências adotadas voluntariamente" (BARBIERI e CAJAZEIRA, 2016, p.174).

As práticas de compliance, foram previstas no ordenamento jurídico pátrio pela primeira vez no inciso VIII, do artigo $7^{\circ}$ da Lei n ${ }^{\circ}$ 12.846/2013 (Lei Anticorrupção), 
VIII- a existência de mecanismos e procedimentos internos de integridade, auditoria e incentivo à denúncia de irregularidades e a aplicação efetiva de códigos de ética e de conduta no âmbito da pessoa jurídica.

Algumas diretrizes e elementos que devem fazer parte dos programas de compliance estão no Decreto no 8420/15 que regulamenta a Lei Anticorrupção e também na Resolução no 909 da Controladoria Geral da União - CGU.

O Capítulo IV do Decreto $n^{\circ} 8420 / 15$ dispõe sobre o Programa de Integridade que, de acordo com o caput do artigo 41, consiste prever no âmbito de uma pessoa jurídica, um conjunto de mecanismos e procedimentos internos de integridade, auditoria e incentivo à denúncia de irregularidades e aplicação efetiva de códigos de ética e de conduta. A saber, a instituição de políticas com o objetivo de detectar e sanar desvios, fraudes, irregularidades e atos ilícitos que sejam praticados contra a administração pública, seja ela nacional ou estrangeira.

Destaque importante merece o referido Capítulo IV, ao explicitar que o programa de integridade deve ser realizado e aplicado de acordo com as características e riscos atuais das atividades de cada pessoa jurídica.

Por sua vez, a Resolução no 909 da Controladoria Geral da União - CGU define que o programa de integridade para ser avaliado por órgãos competentes é preciso fazer constar o relatório de perfil e o relatório de conformidade do programa, definindo por sua vez o que deverá ser indicado no relatório de perfil e o que deve conter no relatório de conformidade.

A importância do compliance para as empresas estatais foi corroborado pelo Estatuto Jurídico das Empresas Estatais- Lei n ${ }^{\circ}$ 13.303/16, bem como pelo Decreto no 8945/16, que o regulamenta em âmbito federal, tamanha a preocupação em combater a corrupção.

Na Lei 13.303/16 a previsão sobre as práticas de compliance estão no artigo $9^{\circ}$, mas é possível encontrar tal instituto em outros dispositivos da referida lei. Um dos principais mecanismos constante no artigo em questão está no $\S 1^{\circ}$ que trata da elaboração do Código de Conduta e de Integridade e, ademais, dispõe sobre princípios, valores e missão da empresa pública e da sociedade de economia mista, bem como orientações sobre a prevenção de conflito de interesses e vedação de atos de corrupção e fraude, assim como menciona as instâncias internas responsáveis pela utilização e aplicação do Código de Conduta e Integridade, sanções em caso de violação do Código e treinamento periódico, no mínimo anual, sobre o Código de Conduta e procedimentos de participação social. 
A elaboração do Código de Conduta e Integridade por parte da Estatal reforça a sua função social que é a vinculação de suas atividades aos propósitos da lei de sua criação, bem como o respeito às normas de ordem trabalhista, ambiental, relativas aos direitos do consumidor, à concorrência, aos investidores e a comunidade à qual está inserida. Ou seja, preconiza que a estatal vá além do mero cumprimento normativo ao exigir que disponha de uma gestão pautada em princípios e valores e, ademais, em preceitos de governança corporativa.

Ao considerar a responsabilidade social como o cumprimento de atribuições que em regra competem ao Estado (TONIN, 2016), a primeira vista parece evidente que as empresas estatais por integrarem a Administração Indireta, ainda que possuindo personalidade jurídica de direito privado, já deveriam desenvolver suas atividades abrangendo as atividades fim da Administração Direta. Ocorre que esta análise se perfaz sopesando um cenário ideal, perfeito, mas infelizmente precisa-se ponderar a responsabilidade social sob o contexto fático das estatais.

Deve-se considerar que as empresas estatais, devido à sua natureza jurídica de direito privado, ainda que mitigada por normas jurídicas de direito público que determinam a realização de licitação e de concurso público, e apesar de vinculadas à imperativos de segurança nacional ou relevante interesse público, precisam ser lucrativas para custearem sua estrutura, proporcionar a realização de investimentos, sem que seja necessária a realização de aporte financeiro por parte do ente federativo que as criaram.

Mas a lucratividade não basta, é preciso ainda que as empresas estatais obedeçam ao arcabouço normativo que as mantenham fiel à lei e à função social que deram causa à sua criação, respeitem as normas de preservação da concorrência, do meio ambiente e consumidores, implementem as medidas previstas apontadas pela Lei de Acesso a Informação, Lei Anticorrupção, Estatuto das Estatais e eventuais decretos ou portarias que as regulamentem, por exemplo.

Mas essa postura de empresa meramente cumpridora de leis atualmente não basta nem mesmo para às empresas privadas, que já precisam atuar com pressupostos valorativos, com um olhar coletivo, demonstrando uma preocupação ética com o meio em que está inserida, seja social ou ambiental.

A sociedade contemporânea está em constante evolução e assim passa a exigir que as empresas, especialmente as empresas estatais contemplem um fim público, estejam integradas 
com os anseios sociais, e possam fazer a diferença na comunidade em que está inserida, razão pela qual as práticas corruptivas não tem mais espaço.

Diante do novo perfil social que tem exigido mudanças na estrutura da Administração Pública e também na atuação das empresas estatais, pode-se considerar que:

\footnotetext{
"O Brasil passou por amadurecimento institucional significativo nos últimos anos. Estamos melhorando. As punições imediatas passaram a atingir o patrimônio e a vida de empresas e de executivos e, principalmente, a imagem das companhias. Ou seja, usar a corrupção como parte do negócio passou a custar caro" (ANTONIK, 2016, p. 49).
}

Assim, afere-se que as empresas estatais estão evoluindo com relação ao combate a corrupção, diversas normas já foram instituídas com este propósito e todas elas remetem para maior transparência nas ações públicas, implementação de medidas anticorrupção que consolidam valores e implantam medidas de controle, incentivando maior participação popular, sendo o compliance a principal delas.

A preocupação normativa com mecanismos voltados a proporcionar maior eficiência nas ações das empresas estatais contribuem de forma significativa no combate à corrupção, já que a burocracia é campo propício para sua ocorrência.

\section{MECANISMOS LEGAIS DE PREVENÇÃo E PUNIÇÃO DE ATOS DE CORRUPÇÃO}

A transformação do perfil da interação social diante da sociedade complexa em que vivemos atualmente está causando uma série de mudanças normativas voltadas ao combate a corrupção nas empresas estatais, já que há recursos públicos envolvidos em suas estruturas e estes devem ser bem investidos, assim como as atividades a serem desenvolvidas pelas estatais precisam ser condizentes com a finalidade para a qual foram criadas.

Com base nesses preceitos, o Código de Conduta e Integridade deverá, inclusive, prever canal de denúncias internas e externas relativas a seu descumprimento e das demais normas internas de ética e obrigacionais, e para incentivar as denúncias deverá haver a previsão de mecanismos de proteção que impeçam qualquer espécie de retaliação a quem utilize o canal de denúncias. 
A Lei das Estatais e o Decreto que a regulamentou trouxeram as práticas de compliance para serem implementadas nas estatais, tendo como principais instrumentos o Código de Conduta e Integridade e as práticas de governança corporativa, gestão de riscos e controle interno, cuja prerrogativa é o combate à corrupção e a consolidação de valores éticos.

O compliance também se revela no novo perfil exigido para os membros do Conselho de Administração e os indicados para cargos de diretor, presidente, diretor-geral, diretor-presidente. Conforme o Artigo 17 do Estatuto exige-se que os ocupantes dos cargos retromencionados deverão ser escolhidos entre cidadãos de reputação ilibada e de notório conhecimento com experiência profissional e formação para o cargo.

Desta forma, procura-se que haja maior envolvimento do corpo diretivo com os resultados e as ações da empresa estatal.

De acordo com o inciso II, do artigo 12 do Estado, e, do inciso II, do artigo 19 do Decreto $\mathrm{n}^{\circ} 8.945 / 16$, as estatais deverão adequar-se constantemente as suas práticas ao Código de Conduta e Integridade e demais regras de boa prática de governança corporativa, na forma estabelecida pelo próprio Decreto e pela Comissão Interministerial de Governança Corporativa e de Administração de Participações Societárias da União - CGPAR.

A governança corporativa é a forma de exercer o poder, que pretende dar maior transparência, proporcionando mais uma forma de controle que objetiva o agir ético dos envolvidos, garantindo atuação dentro das práticas de compliance, portanto, obedecendo normas externas e internas, o que vai repercutir em maior credibilidade da empresa diante da sociedade (AMARAL, 2016).

A governança corporativa, de acordo com o Instituto Brasileiro de Governança Corporativa, "é o sistema pelo qual as empresas e demais organizações são dirigidas, monitoradas e incentivadas, envolvendo os relacionamentos entre sócios, conselho de administração, diretoria, órgãos de fiscalização e controle e demais partes interessadas" (2014, p. 20).

Enquanto que para a ISO 26000, que dispõe sobre as diretrizes de responsabilidade social, a governança corporativa é:

"[...] um importante tema da responsabilidade social amplamente considerada e aplicável a organização de todo tipo e porte. Uma definição simples, mas não menos precisa, é: sistema pelo qual uma organização toma decisões e as implementa na busca de seus objetivos" (ABNT, 2010, def. 2.13). 
Assim, a obrigatoriedade de práticas de governança corporativa pelo Estatuto das Estatais remete a atuação das referidas empresas para se comportarem de forma socialmente responsável, já que precisam se preocupar com as partes interessadas, seja internamente ou externamente, com transparência e participação social. Isso consequentemente aumentará a credibilidade e a viabilidade econômica da empresa a curto, médio e longo prazo, além da realização transparente da prestação de contas (IBGC, 2014).

Ocorre que os mecanismos de prevenção e combate à corrupção podem falhar, seja por meio de denúncias ou de auditoria interna. Caso se detecte a prática de corrupção envolvendo agente público vinculado as estatais e empresas privadas, deve-se aplicar a Lei $\mathrm{n}^{\circ}$ 12.846/2013, a Lei Anticorrupção.

O Capítulo IV da Lei Anticorrupção, trata "Do Processo Administrativo de Responsabilização" - PAR, sendo que o artigo $8^{\circ}$ da referida Lei prevê a instauração e julgamento de processo administrativo para apuração da responsabilidade de pessoa jurídica, e este expediente cabe à autoridade máxima de cada órgão ou entidade dos Poderes Executivo, Legislativo e Judiciário, que agirá de ofício ou mediante provocação, desde que observado o contraditório e a ampla defesa.

O objetivo do Processo Administrativo de Responsabilização - PAR é a apuração de conduta ilícita que causa lesão ao patrimônio público, assim como identificar os envolvidos e suas respectivas participações com o fim de aplicar as sanções previstas no Artigo $6^{\circ}$ da Lei Anticorrupção.

De acordo com a redação do caput do artigo $8^{\circ}$, em uma empresa estatal, a instauração e julgamento caberia à sua autoridade máxima. Mas é preciso definir quem vem a ser a autoridade máxima em uma estatal, já que trata-se de uma entidade pertencente a Administração Pública Indireta e que possui natureza jurídica de direito privado.

A análise do artigo $3^{\circ}$ do Decreto $n^{\circ} 8.420 / 15$ que regulamenta a Lei Anticorrupção em âmbito federal, permite constatar que a competência para instauração e para julgamento do PAR é da autoridade máxima da entidade em face da qual foi praticado o ato lesivo, ou, em cada órgão da administração direta, que neste caso seria o respectivo Ministro de Estado.

A dificuldade desta situação é que há um número muito grande de entidades que podem ser alvo de atos lesivos em âmbito federal e, se as autoridades máximas de todas elas puderem instaurar e julgar o Processo Administrativo de Responsabilização, o problema da 
diversidade de entendimentos que isso pode gerar, causará insegurança jurídica. Por isso de o Comitê anticorrupção se posicionar:

\begin{abstract}
"Defende o Comitê que a centralização possibilita que os profissionais que nele atuem sejam altamente especializados e capacitados com relação à apuração dos fatos lesivos, além de permitir o acúmulo de conhecimento pelo próprio órgão" (MARINELA, PAIVA e RAMALHO, 2015, p. 144).
\end{abstract}

Em que pese o presente trabalho se ater à apreciação das normas de âmbito federal, e devido ao objeto da análise ser a possibilidade da autoridade máxima de uma empresa estatal ter ou não competência para instaurar e julgar processo administrativo de responsabilização, nos valeremos do conteúdo de uma entrevista concedida à $\mathrm{OAB} / \mathrm{SP}$, pelo professor Vicente Greco Filho, em que analisa o Decreto que regulamenta a lei anticorrupção naquele estado, e demonstra ser inconstitucional a possibilidade de pessoas jurídicas de direito privado, como é o caso das estatais, aplicarem sanções às pessoas jurídicas,

\footnotetext{
“Acreditamos que o citado Decreto n ${ }^{\circ} 60.106$, editado para disciplinar a aplicação da lei ao Estado de São Paulo, é eivado de evidente inconstitucionalidade decorrente de errada compreensão da lei federal ao atribuir competência para aplicação de sanções a empresas públicas e sociedades de economia mista, as quais, na verdade, são entidades de Direito Privado.

Veja que o artigo $8^{\circ}$ da Lei Federal dá a entender que a autoridade máxima de qualquer entidade dos poderes executivo, legislativo e judiciário, pelo seu dirigente máximo, poderia instaurar o processo administrativo e aplicar as sanções.

Não se pode esquecer, porém, que o poder executivo tem entidades da administração indireta de Direito Privado e que não podem aplicar sanções a quem quer que seja. A aplicação de medidas punitivas aos particulares, pessoa jurídica ou natural, é privativa de entidades de Direito Público, porque o poder sancionatório é decorrência da chamada potestade administrativa, que somente pessoas jurídicas de Direito Público detêm.

Disso decorre que empresas públicas e sociedades de economia mista, apesar de serem entidades do poder executivo, não a exercem nem podem exercê-la e, consequentemente, não podem instaurar processos administrativos punitivos e muito menos aplicar sanções, como ocorre com o exercício do chamado poder de polícia. Se o fizerem, sua atuação será inconstitucional, por violação do princípio do direito à liberdade de agir e da integridade da pessoa, que somente pode ser restringida pela lei e, no caso de sanção, somente poderá ser aplicada por entidade de Direito Público" (CAASP, 2014)
}

O STF- Supremo Tribunal Federal já decidiu na ADI nº 1.717/2003, em que o objeto do julgamento era a inconstitucionalidade do artigo 58 da Lei ${ }^{\circ}$ 9.649/98, sobre a fiscalização de profissões regulamentadas, e concluiu pela indelegabilidade do poder de polícia, de tributar e de punir à entidade privada. 
Não obstante, o cerne da discussão está no fato de que uma empresa pública ou uma sociedade de economia mista também podem cometer crimes previstos na Lei Anticorrupção e, portanto, também podem sofrer Processo Administrativo de Responsabilização e ao final serem sancionados.

Com o fim de atestar essa situação, novamente destacamos outro trecho da entrevista do professor Vicente Greco Filho à $\mathrm{OAB} / \mathrm{SP}$.

\footnotetext{
“[...] as pessoas jurídicas de Direito Privado, ainda que pertencentes à administração indireta, estão sujeitas à lei comentada, se um de seus agentes praticar atos lesivos em face de pessoa de direito público, estando sujeitas às penas da lei. Imagine-se a hipótese, não impossível ou cerebrina, de uma empresa controlada pelo Estado vier, por meio de um de seus agentes, a corromper um agente federal para obter, por exemplo, uma licença ambiental federal.

Poderá ela ser punida, certamente; ora, sendo assim, como poderia ter o poder de aplicar sanções a empresas concorrentes? Isso sem falar que o dirigente máximo da empresa também pode estar direta ou indiretamente envolvido na corrupção de algum de seus membros ou, por esprit des corps, tenha a tendência de protegê-los. Completa o embasamento constitucional desse entendimento o artigo 173 da Constituição, que coloca a empresa pública e a sociedade de economia mista no plano da atividade econômica e no nível do setor privado, excluindo-lhe, portanto, o poder de aplicar sanções aos administrados, pessoas naturais ou jurídicas. O poder sancionatório é do Estado, enquanto tal e atua por intermédio das pessoas jurídicas de Direito Público" (CAASP, 2014).
}

Sobre essa falta de especificação legal acerca da autoridade máxima de uma empresa estatal poder ou não instaurar e julgar em processo administrativo de responsabilização e devido aos problemas decorrentes de eventuais interpretações equivocadas, o Comitê Anticorrupção opinou pela criação de um órgão que tivesse jurisdição em todo território nacional, vinculado ao Ministério da Justiça e com participação do Ministério Público, para instauração e julgamento dos referidos processos (MARINELA, PAIVA e RAMALHO, 2015).

A pretensão de combate a corrupção nas empresas estatais através da consolidação de valores está nítido nos dispositivos da Lei Anticorrupção, já que conduzindo sua função social de forma ética, cumprindo os deveres legais e sendo economicamente sustentável, aumenta a confiança dos stakholders, que por sua vez também estão envolvidos nas ações das estatais, uma vez que a transparência confere poder a todos de fiscalizarem e denunciarem as ações ilícitas.

Diante dessas considerações, pode-se concluir que a maior preocupação do legislador quanto à adoção de práticas socialmente responsáveis no âmbito das estatais está no sentido 
de nortear suas ações com idoneidade, integridade, ética e valores, pois essa é a expectativa social atual.

Entretanto, ainda assim, na redação dos parágrafos $1^{\circ}, 2^{\circ}$ e $3^{\circ}$ do artigo 27 do Estatuto, que é repetida no artigo 44 do Decreto Federal que o regulamenta, além de conteúdo inerente a função social, pode-se verificar também menção expressa sobre sustentabilidade, que também abrange a ideia de responsabilidade social.

Portanto, o $\S 1^{\circ}$, giza que a função social deve estar presente no interesse coletivo sendo orientada para o alcance do bem-estar econômico e para alocação socialmente eficiente dos recursos geridos pelas estatais, bem como ampliação economicamente sustentada do acesso de consumidores a seus produtos e serviços, desenvolvimento ou utilização de tecnologia brasileira para produção e oferta de produtos e serviços e sempre de maneira economicamente sustentada.

O $\S 2^{\circ}$ se atem a adoção de práticas de sustentabilidade ambiental e de responsabilidade social corporativa compatíveis com o mercado em que atuam.

Já o $§ 3^{\circ}$ dispõe sobre a celebração de convênio entre estatais com pessoas físicas ou jurídicas para promoção de atividades culturais, sociais, esportivas, educacionais e de inovação tecnológica. A redação do Decreto no 8945/16, no entanto, vai um pouco além, ao mencionar novamente no inciso III a preocupação com atos de corrupção ou fraude, exigindo análise prévia do histórico da instituição que será beneficiada e se há controles e políticas de integridade na instituição.

Mas a preocupação do decreto igualmente dá-se no sentido de dissociar as estatais de qualquer influência ou favorecimento político-partidário, ao especificar no inciso VI do $\S 3^{\circ}$ a vedação das estatais celebrarem convênio com dirigente de partido político, titular de mandato eletivo, empregado ou administrador da empresas estatal, com seus parentes consanguíneos ou afins até terceiro grau, e também com pessoa jurídica cujo proprietário ou administrador seja uma dessas pessoas.

Assim, a mudança da concepção social que exige o combate à corrupção, pleiteia um papel mais ativo dos envolvidos como agentes fiscalizadores capazes de fazer denúncias e participar da gestão pública, requerendo que as estatais efetivamente cumpram o papel para qual foram instituídas, não mais permitindo práticas patrimonialistas de confusão entre o público e o privado. 
Ocorre que a sociedade não se contenta mais com a atuação de empresas estatais meramente cumpridora de leis, razão pela qual a adoção, consolidação e difusão de valores éticos é fundamental para o fortalecimento e credibilidade dessas empresas, que precisam ser lucrativas, mas também precisam efetivamente auxiliar o Estado - a Administração Direta na consecução de suas atividades fim, alicerçando seu papel social e sua preocupação com o meio a qual está inserido.

\section{CONSIDERAÇÕES FINAIS}

Conclui-se que o papel social desempenhado pelas empresas estatais não correspondiam às premissas de sua constituição, fazendo com que as mesmas fossem vítimas de diversas ingerências políticas com o fim de atender aos anseios de interesses políticos.

A falta de qualificação e perfil dos dirigentes das referidas empresas, que em sua maioria eram indicações políticas, refletiram na falta de compromisso dos dirigentes das referidas empresas com a qualidade, a lucratividade e a sociedade, tornando as estatais um ambiente favorável à prática de corrupção.

Após vários escândalos envolvendo corrupção nas estatais, diversas normas começaram a ser introduzidas no ordenamento jurídico com o fim de combater desvios e malfeitos. Ao traçar requisitos objetivos exigindo qualificação para os ocupantes de cargos de alto escalão, pretende-se não outra coisa senão fazer com que haja mais envolvimento e compromisso com as atividades dessas empresas.

No mais, o combate à corrupção também consiste nas práticas de compliance estabelecidas, onde pretende-se efetivar a consolidação de valores e princípios através da constituição do Código de Conduta e Integridade, e assim fixar uma postura ética.

Dentre as principais práticas de compliance está a busca por maior transparência nas ações das estatais, a fim de que a sociedade possa acompanhar, fiscalizar e denunciar eventuais práticas de corrupção.

Caso as medidas preventivas de combate à corrupção não tenham êxito, a Lei Anticorrupção prevê a instauração do Processo Administrativo de Responsabilização - PAR, para investigar e punir aquelas pessoas jurídicas que causarem prejuízos ao erário público. Entretanto, no caso das estatais, por deterem natureza jurídica de direito privado e devido a 
possibilidade de causarem prejuízo as finanças públicas, ou por serem vítimas do prejuízo, ainda falta esclarecimento sobre quem possui capacidade para instaurar e aplicar sanções.

Assim, o Estatuto das empresas estatais e o Decreto federal que o regulamenta nortearam as práticas de responsabilidade social das estatais ao combate à corrupção, sem deixar de fora a preocupação com o meio ambiente, o incentivo ao esporte e a cultura.

Não obstante as empresas estatais possuem uma função social que é definida por lei, e que deve nortear as atividades das estatais desde sua criação, possuindo efeito vinculante, por esta razão não se confunde com responsabilidade social.

Portanto, a implantação e a consolidação de valores nas empresas estatais, somadas à ações mais transparentes e abertas à participação social é uma mudança de grande relevância e que pode levar ao combate efetivo da corrupção. Contudo, resta ainda alcançar parâmetros que pacifiquem a aplicabilidade do PAR- Processo Administrativo de Responsabilização por parte das Empresas Estatais. Um desafio que permanece, até o momento, em aberto.

\section{REFERÊNCIAS}

AMARAL, Paulo Osternack. Lei das Estatais: Espectro de Incidência e regras de governança. In: JUSTEN FILHO, Marçal (org.). Estatuto Jurídico das Empresas Estatais: Lei 13.303/2016- "Lei das Estatais". São Paulo: Revista dos Tribunais, 2016. p. 58- 70.

ANTONIK, Luis Roberto. Compliance, ética, responsabilidade social e empresarial: Uma visão prática. Rio de Janeiro: Alta Books, 2016.

ASSOCIAÇÃO BRASILEIRA DE NORMAS TÉCNICAS (ABNT). NBR ISO 26000. Diretrizes de responsabilidade social. Rio de Janeiro, 2010.

BANDEIRA DE MELlO, Celso Antônio. Curso de Direito Administrativo. 2.ed. rev. e atual. São Paulo: Malheiros, 2012.

BARBIERI, José Carlos; CAJAZEIRA, Jorge Emanuel Reis. Responsabilidade Social Empresarial e Empresa Sustentável. São Paulo: Saraiva, 2016.

BRASIL. Constituição (1988). Constituição da República Federativa do Brasil. Disponível em: <http://www.planalto.gov.br/ccivil_03/constituicao/constituicao.htm>.Acesso em: 15 abr. 2017. 
BRASIL. Lei $\mathrm{n}^{\circ}$ 8.429, de 2 de junho de 1992. Dispõe sobre as sanções aplicáveis aos agentes públicos nos casos de enriquecimento ilícito no exercício de mandato, cargo, emprego ou função na administração pública direta, indireta ou fundacional e dá outras providências. Diário Oficial da União, Brasília, DF, 3 jun.1992. Disponível em: <http://www.planalto.gov.br/ccivil_03/leis/L8429.htm>. Acesso em: 29 abr.2017.

BRASIL. Lei no 12.527, de 18 de novembro de 2011. Regula o acesso a informação. Diário Oficial da União, Brasília, DF, 18 nov. 2011. Disponível em: <http://www.planalto.gov.br/ccivil_03/_ato2011-2014/2011/lei/112527.htm>. Acesso em: 27 abr. 2017.

BRASIL. Lei $\mathrm{n}^{\mathrm{o}} 12.846$, de $1^{\circ}$ de agosto de 2013. Dispõe sobre a responsabilização administrativa e civil de pessoas jurídicas pela prática de atos contra a administração pública, nacional ou estrangeira, e dá outras providências. Diário Oficial da União, Brasília, DF, 2 ago. 2013. Disponível em: <http://www.planalto.gov.br/ccivil_03/_ato20112014/2013/lei/112846.htm>. Acesso em: 29 abr.2017.

BRASIL. Decreto $\mathrm{n}^{\circ}$ 8.420, de 18 de março de 2015. Regulamenta a Lei $\mathrm{n}^{\mathrm{o}} 12.846$, de $1^{\circ}$ e agosto de 2013, que dispõe sobre a responsabilização administrativa de pessoas jurídicas pela prática de atos contra a administração pública, nacional ou estrangeira e dá outras providências. Diário Oficial da União, Brasília, DF, 19 mar. 2015. Disponível em: <http://www.planalto.gov.br/ccivil_03/_Ato2015-2018/2015/Decreto/D8420.htm>. Acesso em: 29 abr.2017.

BRASIL. Ministério da Transparência, Fiscalização e Controladoria-Geral da União. Portaria n 909, de 7 de abril de 2015. Relator Valdir Moysés Simão, Ministro de Estado Chefe da Controladoria-Geral da União. Diário Oficial da União, Brasília, DF, 7 abr. 2015. Disponível em: <www.cgu.gov.br/sobre/legislacao/arquivos/portarias/portaria_cgu_909_2015.pdf>. Acesso em: 28 abr. 2017.

BRASIL. Lei $\mathrm{n}^{\circ}$ 13.303, de 30 de junho de 2016. Dispõe sobre o estatuto jurídico da empresa pública, da sociedade de economia mista e de suas subsidiárias, no âmbito da União, dos Estados, do Distrito Federal e dos Municípios. Diário Oficial da União, Brasília, DF, 1 de jul. 2016. Disponível em: <http://www.planalto.gov.br/ccivil_03/_ato20152018/2016/lei/L13303.htm>. Acesso em: 15 abr.2017.

BRASIL. Decreto $\mathrm{n}^{\circ}$ 8.945, de 27 de dezembro de 2016. Regulamenta, no âmbito da União, a Lei $\mathrm{n}^{\mathrm{o}}$ 13.303, de 30 de junho de 2016, que dispõe sobre o estatuto jurídico da empresa pública, da sociedade de economia mista e de suas subsidiárias, no âmbito da União, dos Estados, do Distrito Federal e dos Municípios. Diário Oficial da União, Brasília, DF, 28 dez. 2016. Disponível em: <http://www.planalto.gov.br/ccivil_03/_ato20152018/2016/decreto/D8945>.htm. Acesso em 15 abr.2017.

CAOLI, Cristiane; ALVARENGA, Darlan; LAPORTA, Taís. Petrobras tem $1^{\circ}$ prejuízo desde 1991; perda com corrupção é de R\$ 6,2 bi. G1, Rio de Janeiro/São Paulo, Negócios. 
Disponível em: <http://g1.globo.com/economia/negocios/noticia/2015/04/petrobras-divulgabalanco-auditado-com-prejuizo-de-r-216-bi-em-2014.html>. Acesso em 18 abr. 2017.

CARDOSO, André Guskow. Governança Corporativa, transparência e compliance nas empresas estatais: O regime instituído pela Lei 13.303/2016. In: JUSTEN FILHO, Marçal (org.). Estatuto Jurídico das Empresas Estatais: Lei 13.303/2016- "Lei das Estatais". São Paulo: Revista dos Tribunais, 2016. p. 94- 119.

CONTROLADORIA - GERAL DA UNIÃO. Secretaria de prevenção da corrupção e informações estratégicas. Controle Social: orientação dos cidadãos para participação na gestão pública e no exercício do controle social. Disponível em: <http://www.cgu.gov.br/Publicacoes/controle-social/arquivos/controlesocial2012.pdf>.

Acesso em 29 abr. 2017.

GRECO FILHO, Vicente. Leia entrevista de Vicente Greco Filho sobre a nova lei de combate à corrupção. CAASP, 26 mar. 2014. Disponível em: <http://www.caasp.org.br/noticias.asp?cod_noticia=2824>. Acesso em: 29 abr. 2017.

INSTITUTO BRASILEIRO DE GOVERNANÇA CORPORATIVA (IBGC). Códigos e melhores práticas de governança corporativa. 5. Ed. São Paulo: IBGC, 2014.

MARINELA, Fernanda; PAIVA, Fernando; RAMALHO, Tatiany. Lei Anticorrupção: Lei $\mathrm{n}^{\mathrm{o}}$ 12.846, de $1^{\circ}$ de agosto de 2013. São Paulo: Saraiva, 2015.

MELO, LUISA. Política de preços deve ajudar Petrobras a vender refinarias. EXAME, São Paulo. Disponível em: <http://exame.abril.com.br/negocios/politica-de-precos-deve-ajudarpetrobras-a-vender-refinarias/>. Acesso em: 18 abr. 2017.

Petrobras vive sua pior crise de credibilidade. Gazeta do Povo, Curitiba, 22 março 2014, Vida Pública. Disponível em: <http://www.gazetadopovo.com.br/vida-publica/petrobrasvive-sua-pior-crise-de-credibilidade-20s5f96t4zyqcoy69iktdyc7i>. Acesso em: 18 abr. 2017.

Prejuízo com preços controlados sobe 55\% e Petrobras busca alta da gasolina. UOL, São Paulo, 8 de agosto 2014, Economia. Disponível em: $<$ https://economia.uol.com.br/noticias/redacao/2014/08/08/prejuizo-com-precos-controladossobe-55-e-petrobras-busca-alta-da-gasolina.htm>. Acesso em: 18 abr. 2017.

TONIN, Mayara Gasparoto. Função Social das empresas estatais. In: JUSTEN FILHO, Marçal (org.). Estatuto Jurídico das Empresas Estatais: Lei 13.303/2016- "Lei das Estatais". São Paulo: Revista dos Tribunais, 2016. p.265-282. 